\title{
Television Viewing Time and Breast Cancer Incidence for Japanese Premenopausal and Postmenopausal Women: The JACC Study
}

\author{
Jinhong Cao, MD, $\mathrm{PhD}{ }^{1}$ \\ Ehab Salah Eshak, MD, PhD ${ }^{1,2}$ \\ Keyang Liu, MD, PhD' \\ Isao Muraki, MD, PhD' \\ Renzhe Cui, MD, $P D^{1}$ \\ Hiroyasu Iso, MD, PhD, MPH \\ Akiko Tamakoshi, MD, $\mathrm{PhD}^{3}$ \\ JACC Study Group*
}

${ }^{1}$ Public Health, Department of Social Medicine, Osaka University Graduate School of Medicine, Osaka, Japan, ${ }^{2}$ Department of Public Health, Community and Preventive Medicine, Faculty of Medicine, Minia University, Minia, Egypt, ${ }^{3}$ Department of Public Health, Faculty of Medicine, Hokkaido University, Sapporo, Japan

Correspondence: Hiroyasu Iso, MD, $\mathrm{PhD}, \mathrm{MPH}$ Department of Social Medicine,

Osaka University Graduate School of Medicine,

2-2 Yamadaoka, Suita-shi, Osaka 565-0871, Japan

Tel: 81-6-6879-3911

Fax: 81-6-6879-3919

E-mail: iso@pbhel.med.osaka-u.ac.jp

Received December 21, 2018

Accepted March 16, 2019

Published Online March 21, 2019

${ }^{*}$ The members of the group are listed at the end of this article.

\begin{abstract}
Purpose
The evidence on effects of TV viewing time among premenopausal and postmenopausal
\end{abstract} women for breast cancer risk remains controversial and limited.

\section{Materials and Methods}

A prospective study encompassing 33,276 (17,568 premenopausal, and 15,708 postmenopausal) women aged 40-79 years in whom TV viewing time, menstrual, and reproductive histories were determined by a self-administered questionnaire. The follow-up was from 1988 to 2009 and hazard ratios (HRs) with 95\% confidence intervals (Cls) of breast cancer incidence were calculated for longer TV viewing time in reference to shorter TV viewing time by Cox proportional hazard models.

\section{Results}

During 16.8-year median follow-up, we found positive associations between TV viewing time and breast cancer incidence with a borderline significant trend among total women and a significant trend among postmenopausal women. Among total women, the multivariable HRs $(95 \% \mathrm{Cls})$ for risk of breast cancer in reference to $<1.5 \mathrm{hr} /$ day of TV viewing time were 0.89 (0.59-1.34) for 1.5 to $<3.0 \mathrm{hr} /$ day, 1.19 (0.82-1.74) for 3.0 to $<4.5 \mathrm{hr} /$ day, and 1.45 (0.91-2.32) for $\geq 4.5 \mathrm{hr} /$ day ( $\mathrm{p}$ for trend=0.053) and among postmenopausal women, the corresponding risk estimates were 1.10 (0.42-2.88), 2.54 (1.11-5.80), and 2.37 (0.926.10) ( $p$ for trend=0.009), respectively.

\section{Conclusion}

Prolonged TV viewing time was associated with increased risk of breast cancer, especially among postmenopausal women.

\section{Introduction}

Television (TV) viewing time is a sedentary time along with less activity and it is an important leisure behavior in women daily routines [1,2]. The average hours spent in watching TV has been reported to be about $5 \mathrm{hr} /$ day in the US adults and 3-4 hr/ day in Japanese adults [3,4].

Breast cancer is the most common cancer among Japanese women (19.0\% of female cancers) [5], and have markedly

\section{Key words}

Television viewing time, Breast neoplasms, Incidence, Cohort study, Postmenopausal, Body mass index, Japan 
the associations of prolonged TV viewing times with risks of lung, colon and endometrial cancers, but failed to conclude any association with breast cancer [2]. In addition, findings of the Black Women's Health Study indicated that the association between TV viewing time and risk of breast cancer was evident for total and postmenopausal women, but not for premenopausal women [11], while an Indian case-control study showed no increased risk for both premenopausal and postmenopausal women [9].

Therefore, we thought to assess the association of TV viewing time for premenopausal and postmenopausal Japanese women with risk of breast cancer in a large population-based Japanese study, the Japan Collaborative Cohort (JACC) study. As the mechanisms underlying the increased risk for breast cancer with prolonged TV viewing were more evident after menopause, we hypothesize that long TV viewing time may be associated with increased risk of breast cancer incidence in Japanese postmenopausal women.

\section{Materials and Methods}

\section{Study population and ascertainment of breast cancer}

Details of the study subjects have been described elsewhere [15]. Briefly, the baseline data of the JACC Study were collected from 1988 to 1990 and 64190 women aged 40 to 79 years in 45 study areas throughout Japan participated in the study. In 24 areas out of the 45 study areas, data on cancer incidence such as the date of diagnosis and the primary site of cancer were collected simultaneously through populationbased cancer registries or by reviewing the records of local and major hospitals from the baseline to the end of 2009. Some study areas discontinued the follow-up survey regarding cancer before 2009 (1994 in one study area, 1997 in two areas, 1999 in one area, 2000 in one area, 2002 in one area, 2003 in one area, 2006 in two areas, and 2008 in two areas).

We confined the analysis to women from these 24 areas where cancer incidence information are available $(n=36,255)$. Excluding data of women with previous diagnosis of breast cancer $(\mathrm{n}=11)$, and women with missing data on TV viewing time $(\mathrm{n}=2,979)$ left a total of $33,276(17,568$ premenopausal and 15,708 postmenopausal) women for the analysis. This study was sponsored by the Ministry of Education, Sports and Science.

\section{Exposure and other covariates assessment}

Participants completed a self-administered questionnaire including information on TV viewing time, age, family his- tory of diseases, histories of hypertension, diabetes mellitus, cardiovascular diseases and cancer, height, weight, education background, smoking status, alcohol drinking habit, physical activity, mental stress, dietary habits, reproductive and menstrual history, menopause, and hormone use. Body mass index (BMI) was calculated by dividing the weight in kilograms by the square of height in meters. We obtained information about the average TV viewing time on weekdays during the preceding year. The average TV viewing time per day was classified into four categories: $<1.5,1.5$ to $<3.0,3.0$ to $<4.5$, and $\geq 4.5 \mathrm{hr} /$ day. Fractions hours were rounded off (e.g., 1.5 to $<3$ hours represented responses from 1.5 to 2.9 hours).

\section{Statistical analysis}

Mean values (standard deviations) and proportions of baseline risk characteristics were calculated, and the linear trends in those variables according to TV viewing time were tested by the linear regression analysis for continuous variables and the logistic regression analysis for proportional variables. Person-years of follow-up were calculated from the responding date to the baseline questionnaire until the obtainment of one out of four possible endpoints as follows: (1) incidence of breast cancer event, (2) relocation from the study area, (3) the end of the study on December 31, 2009, or (4) death.

Cox proportional hazard regression age- and multivariable-adjusted models were used to estimate the hazard ratios (HRs) with 95\% confidence intervals (CIs) for breast cancer incidence according to TV viewing time categories (1.5 to $<3.0,3.0$ to $<4.5$, and $\geq 4.5 \mathrm{hr} /$ day) in reference to $<1.5 \mathrm{hr} /$ day. The confounding factors included age (continuous), age of menarche ( $<14,14-15$, and $>15$ years), age of menopause $(<45,45-50$, and $>50$ years), type of menopause (nature or operation), BMI (continuous), currently married (yes or no), smoking status (never, ex-smoker, and current smoker), alcohol intake (never, ex-drinker, and current drinker of 0.1-22.9, 23.0-45.9, and $\geq 46.0 \mathrm{~g}$ ethanol / day), parity ( $0,1,2$, and $\geq 3$ ), use of sex hormone (yes or no), family history of breast cancer (yes or no), daytime napping (yes or no), sleep duration $(\leq 6,7$, and $\geq 8 \mathrm{hr} /$ day), stress (high, median, or low), education $(\leq 12,13-15,16-18$, and $\geq 19$ years), and history of diabetes (yes or no). In a final model, we adjusted further for sport time per week (never, $<1,1-2,3-4$, and $\geq 5 \mathrm{hr} / \mathrm{wk}$ ) and walking time per day (never, $<30,30-60$, and $\geq 60 \mathrm{~min} /$ day). The stratification analyses were planned to test the effect modification by potential effect modifiers such as menopausal status, BMI, history of diabetes, and smoking status. However, due to limited number of participants or breast cancer cases in the diabetic or smoking women categories, these stratification analyses were performed for menopausal 
Table 1. Distributions of potential risk factors in premenopausal and postmenopausal women according to television viewing time

\begin{tabular}{|c|c|c|c|c|c|}
\hline \multirow{2}{*}{ Parameter } & \multicolumn{4}{|c|}{ Television viewing time (hr) } & \multirow{2}{*}{$\begin{array}{l}p \text { for } \\
\text { trend }\end{array}$} \\
\hline & $<1.5$ & 1.5 to $<3.0$ & 3 to $<4.5$ & $\geq 4.5$ & \\
\hline \multicolumn{6}{|l|}{ Total women } \\
\hline No. at risk & 8,756 & 9,615 & 12,908 & 4,976 & \\
\hline Age, mean \pm SD (yr) & $56.6 \pm 10.5$ & $56.3 \pm 9.9$ & $58.4 \pm 9.7$ & $62.2 \pm 9.4$ & $<0.001$ \\
\hline Menarche age, mean \pm SD (yr) & $14.9 \pm 1.8$ & $14.8 \pm 1.7$ & $15.0 \pm 1.7$ & $15.0 \pm 1.8$ & $<0.001$ \\
\hline Body mass index, mean $\pm \mathrm{SD}\left(\mathrm{kg} / \mathrm{m}^{2}\right)$ & $22.6 \pm 3.0$ & $22.8 \pm 3.0$ & $23.0 \pm 3.1$ & $23.3 \pm 3.4$ & $<0.001$ \\
\hline \multicolumn{6}{|l|}{ Parity (number of children) (\%) } \\
\hline 0 & 5.2 & 3.6 & 4.5 & 7.0 & $<0.001$ \\
\hline 1 & 6.4 & 6.5 & 8.0 & 9.5 & \\
\hline 2 & 34.6 & 38.9 & 37.7 & 33.4 & \\
\hline$\geq 3$ & 53.9 & 51.0 & 49.9 & 50.1 & \\
\hline Family history of breast cancer in mother or sisters $(\%)$ & 1.3 & 1.5 & 1.4 & 1.3 & 0.152 \\
\hline Education < 15 yr $(\%)$ & 23.4 & 22.6 & 25.7 & 32.6 & $<0.001$ \\
\hline Currently married $(\%)$ & 85.8 & 86.8 & 82.2 & 72.6 & $<0.001$ \\
\hline Sleep duration, mean \pm SD (hr/ day) & $7.0 \pm 1.1$ & $7.0 \pm 1.0$ & $7.1 \pm 1.1$ & $7.1 \pm 1.2$ & $<0.001$ \\
\hline Daytime napping $(\%)$ & 27.1 & 27.7 & 30.6 & 36.9 & $<0.001$ \\
\hline Sport time $\geq 3 \mathrm{hr} / \mathrm{wk}(\%)$ & 8.8 & 9.6 & 9.9 & 10.5 & 0.121 \\
\hline Walking time $\geq 60 \mathrm{~min} /$ day $(\%)$ & 52.0 & 52.2 & 50.1 & 43.1 & $<0.001$ \\
\hline \multicolumn{6}{|l|}{ Smoking $(\%)$} \\
\hline Never smoker & 86.8 & 86.1 & 83.6 & 76.3 & $<0.001$ \\
\hline Former smoker & 1.1 & 1.0 & 14.0 & 2.4 & \\
\hline Current smoker & 3.3 & 3.7 & 4.6 & 7.3 & \\
\hline Alcohol intake, mean \pm SD (g ethanol/day) & $9.5 \pm 12.8$ & $9.4 \pm 12.7$ & $9.2 \pm 12.1$ & $11.0 \pm 13.8$ & $<0.001$ \\
\hline High stress $(\%)$ & 15.7 & 16.8 & 18.8 & 21.4 & $<0.001$ \\
\hline Hormone use $(\%)$ & 5.1 & 4.8 & 4.8 & 5.3 & 0.096 \\
\hline History of diabetes $(\%)$ & 3.6 & 3.3 & 4.2 & 7.7 & $<0.001$ \\
\hline \multicolumn{6}{|l|}{ Premenopausal women } \\
\hline No. at risk & 4,371 & 4,964 & 6,241 & 1,992 & \\
\hline Age, mean \pm SD (yr) & $52.3 \pm 10.7$ & $52.7 \pm 10.2$ & $55.2 \pm 10.4$ & $59.8 \pm 10.8$ & $<0.001$ \\
\hline Menarche age, mean \pm SD (yr) & $14.6 \pm 1.7$ & $14.6 \pm 1.7$ & $14.8 \pm 1.7$ & $15.1 \pm 1.8$ & $<0.001$ \\
\hline Body mass index, mean $\pm \mathrm{SD}\left(\mathrm{kg} / \mathrm{m}^{2}\right)$ & $22.4 \pm 2.9$ & $22.7 \pm 2.9$ & $23.0 \pm 3.1$ & $23.2 \pm 3.3$ & $<0.001$ \\
\hline \multicolumn{6}{|l|}{ Parity (number of children) $(\%)$} \\
\hline 0 & 5.4 & 3.6 & 4.4 & 6.9 & $<0.001$ \\
\hline 1 & 5.9 & 6.4 & 7.9 & 9.6 & \\
\hline 2 & 39.9 & 43.6 & 41.2 & 34.9 & \\
\hline$\geq 3$ & 39.9 & 43.6 & 41.2 & 34.9 & \\
\hline Family history of breast cancer in mother or sisters (\%) & 1.4 & 1.7 & 1.5 & 0.9 & 0.019 \\
\hline Education < 15 yr $(\%)$ & 16.8 & 16.5 & 20.0 & 29.0 & $<0.001$ \\
\hline Currently married $(\%)$ & 89.2 & 89.7 & 85.8 & 77.6 & $<0.001$ \\
\hline Sleep duration (hr/day) & $7.0 \pm 1.0$ & $7.0 \pm 1.0$ & $7.1 \pm 1.0$ & $7.2 \pm 1.2$ & $<0.001$ \\
\hline Daytime napping $(\%)$ & 23.9 & 25.4 & 28.5 & 36.8 & $<0.001$ \\
\hline Sport time $\geq 3 \mathrm{hr} / \mathrm{wk}(\%)$ & 7.9 & 8.3 & 8.4 & 9.7 & 0.022 \\
\hline Walking time $\geq 60 \mathrm{~min} /$ day $(\%)$ & 52.1 & 50.2 & 48.3 & 42.8 & $<0.001$ \\
\hline \multicolumn{6}{|l|}{ Smoking $(\%)$} \\
\hline Never smoker & 89.2 & 87.8 & 86.1 & 79.8 & $<0.001$ \\
\hline Former smoker & 1.0 & 0.9 & 1.3 & 2.0 & \\
\hline Current smoker & 3.7 & 4.6 & 5.3 & 8.9 & \\
\hline Alcohol intake, mean \pm SD (g ethanol/day) & $9.2 \pm 12.8$ & $10.0 \pm 14.2$ & $9.9 \pm 12.5$ & $12.2 \pm 17.1$ & $<0.001$ \\
\hline
\end{tabular}

(Continued to the next page) 
Table 1. Continued

\begin{tabular}{|c|c|c|c|c|c|}
\hline \multirow{2}{*}{ Parameter } & \multicolumn{4}{|c|}{ Television viewing time (hr) } & \multirow{2}{*}{$\begin{array}{l}\mathrm{p} \text { for } \\
\text { trend }\end{array}$} \\
\hline & $<1.5$ & 1.5 to $<3.0$ & 3 to $<4.5$ & $\geq 4.5$ & \\
\hline High stress (\%) & 14.1 & 15.5 & 17.0 & 19.0 & $<0.001$ \\
\hline Hormone use $(\%)$ & 5.5 & 5.2 & 5.1 & 5.3 & 0.953 \\
\hline History of diabetes $(\%)$ & 2.6 & 2.3 & 3.2 & 5.7 & $<0.001$ \\
\hline \multicolumn{6}{|l|}{ Postmenopausal women } \\
\hline No. at risk & 3,666 & 3,914 & 5,608 & 2,520 & \\
\hline Age, mean $\pm S D(y r)$ & $61.0 \pm 7.8$ & $60.3 \pm 7.3$ & $61.3 \pm 7.5$ & $63.5 \pm 7.4$ & $<0.001$ \\
\hline Menarche age, mean \pm SD (yr) & $15.4 \pm 1.8$ & $15.1 \pm 1.8$ & $15.1 \pm 1.7$ & $15.0 \pm 1.8$ & $<0.001$ \\
\hline Menopause age, mean \pm SD (yr) & $48.5 \pm 4.8$ & $48.6 \pm 4.6$ & $48.7 \pm 4.7$ & $48.7 \pm 4.8$ & 0.662 \\
\hline Natural menopause (\%) & 87.3 & 87.5 & 87.1 & 87.2 & 0.915 \\
\hline Body mass index, mean $\pm \mathrm{SD}\left(\mathrm{kg} / \mathrm{m}^{2}\right)$ & $22.8 \pm 3.1$ & $22.9 \pm 3.1$ & $23.0 \pm 3.1$ & $23.3 \pm 3.5$ & $<0.001$ \\
\hline \multicolumn{6}{|l|}{ Parity (number of children) (\%) } \\
\hline 0 & 2.9 & 2.5 & 2.9 & 5.1 & $<0.001$ \\
\hline 1 & 6.7 & 6.5 & 8.3 & 9.7 & \\
\hline 2 & 29.6 & 34.2 & 33.5 & 33.4 & \\
\hline$\geq 3$ & 60.8 & 56.9 & 54.0 & 51.7 & \\
\hline Family history of breast cancer in mother or sisters $(\%)$ & 1.2 & 1.2 & 1.3 & 1.6 & 0.652 \\
\hline Education < 15 yr $(\%)$ & 26.4 & 27.7 & 29.2 & 32.5 & $<0.001$ \\
\hline Currently married (\%) & 82.1 & 83.5 & 78.7 & 69.5 & $<0.001$ \\
\hline Sleep duration, mean \pm SD (hr/ day) & $7.1 \pm 1.1$ & $7.1 \pm 1.1$ & $7.1 \pm 1.1$ & $7.1 \pm 1.1$ & 0.379 \\
\hline Daytime napping (\%) & 30.3 & 30.7 & 32.4 & 35.7 & $<0.001$ \\
\hline Sport time $\geq 3 \mathrm{hr} / \mathrm{wk}(\%)$ & 10.8 & 11.0 & 11.3 & 10.8 & 0.372 \\
\hline Walking time $\geq 60 \mathrm{~min} /$ day $(\%)$ & 52.0 & 52.2 & 50.1 & 43.1 & $<0.001$ \\
\hline \multicolumn{6}{|l|}{ Smoking $(\%)$} \\
\hline Never smoker & 86.5 & 84.6 & 82.0 & 75.2 & $<0.001$ \\
\hline Former smoker & 1.3 & 1.2 & 1.6 & 2.5 & \\
\hline Current smoker & 2.8 & 2.5 & 3.6 & 6.0 & \\
\hline Alcohol intake, mean \pm SD (g ethanol/day) & $9.7 \pm 13.1$ & $8.2 \pm 10.0$ & $8.2 \pm 11.1$ & $10.1 \pm 11.2$ & 0.005 \\
\hline High stress $(\%)$ & 19.2 & 19.1 & 21.8 & 23.8 & $<0.001$ \\
\hline Hormone use $(\%)$ & 4.5 & 4.3 & 4.5 & 5.4 & 0.006 \\
\hline History of diabetes $(\%)$ & 4.6 & 4.4 & 5.4 & 9.3 & $<0.001$ \\
\hline
\end{tabular}

SD, standard deviation.

status and BMI only. Values for p-interaction were calculated for cross-product terms of menopausal status (dichotomous) or BMI (continuous) with TV viewing time (hr/day). We used SAS ver. 9.4 software (SAS Institute Inc., Cary, NC) for the statistical analyses. All statistical tests were 2-tailed and values of $\mathrm{p}<0.05$ were regarded as significant.

\section{Ethical statement}

Informed consent was obtained from participants asking their will to participate to the JACC study in the baseline questionnaire; but in some areas, it was obtained from the representative of those areas. The ethics committees of Nagoya University School of Medicine and Osaka University approved the protocol of this study.

\section{Results}

In 607,295 person years of follow-up for 33,276 women, 247 (170 premenopausal and 77 postmenopausal) cases of breast cancer were newly diagnosed. The most frequent selfreported daily TV viewing time was 2.0 hours among our sample of women, with an average of 2.9 hours. Table 1 shows the baseline characteristics of women according to TV viewing time. Among total women, those with longer TV viewing time were more likely to be older and to have higher BMI, lower educational level and longer daytime napping. They were also more likely to be currently smokers and diabetics and to have high mental stress. Although premenopausal and postmenopausal women showed similar trends 
Table 2. Hazard ratios of breast cancer incidence according to television viewing time for total women

\begin{tabular}{|c|c|c|c|c|c|}
\hline & \multicolumn{4}{|c|}{ Television viewing time $(\mathbf{h r})$} & \multirow{2}{*}{$\begin{array}{l}p \text { for } \\
\text { trend }\end{array}$} \\
\hline & $<1.5$ & 1.5 to $<3.0$ & 3 to $<4.5$ & $\geq 4.5$ & \\
\hline Person-years & 147,018 & 166,514 & 216,718 & 77,045 & \\
\hline Breast cancer & 46 & 58 & 100 & 43 & \\
\hline Age-adjusted HR (95\% CI) & 1.00 & $1.13(0.77-1.67)$ & $1.57(1.11-2.23)$ & $2.03(1.33-3.09)$ & $<0.001$ \\
\hline Multivariable HR $(95 \% \mathrm{CI})^{\mathrm{a})}$ & 1.00 & $0.93(0.62-1.40)$ & $1.25(0.86-1.81)$ & $1.55(0.98-2.46)$ & 0.028 \\
\hline Multivariable HR $(95 \% \text { CI })^{\text {b) }}$ & 1.00 & $0.89(0.59-1.34)$ & $1.19(0.82-1.74)$ & $1.45(0.91-2.32)$ & 0.053 \\
\hline
\end{tabular}

$\mathrm{HR}$, hazard ratio; CI, confidence interval. a) Adjusted for age, age of menarche, body mass index, parity, family history of breast cancer, education level, married status, daytime napping, sleep duration, mental stress, alcohol intake, hormone use, smoking status, and history of diabetes, b)Adjusted further for sport time (never, 1-2, 3-4, and $\geq 5 \mathrm{hr} / \mathrm{wk}$ ) and walking time (never, $<30,30-60$, and $\geq 60 \mathrm{~min} /$ day).

Table 3. Hazard ratios of breast cancer incidence according to television viewing time, stratified by menopausal status and body mass index

\begin{tabular}{|c|c|c|c|c|c|}
\hline & \multicolumn{4}{|c|}{ Television viewing time (hr) } & \multirow{2}{*}{$\begin{array}{l}\mathrm{p} \text { for } \\
\text { trend }\end{array}$} \\
\hline & $<1.5$ & 1.5 to $<3.0$ & 3 to $<4.5$ & $\geq 4.5$ & \\
\hline \multicolumn{6}{|l|}{ Premenopausal wom } \\
\hline Person-years & 91,678 & 104,460 & 132,916 & 42,948 & \\
\hline No. of breast cancers & 34 & 44 & 63 & 29 & \\
\hline Age-adjusted HR (95\% CI) & 1.00 & $1.17(0.75-1.83)$ & $1.39(0.91-2.11)$ & $2.13(1.28-3.53)$ & 0.005 \\
\hline Multivariable HR $(95 \% \text { CI })^{\mathrm{a})}$ & 1.00 & $0.88(0.55-1.41)$ & $0.95(0.60-1.49)$ & $1.41(0.80-2.49)$ & 0.388 \\
\hline Multivariable HR $\left.(95 \% \text { CI })^{\mathrm{b}}\right)$ & 1.00 & $0.85(0.58-1.43)$ & $0.91(0.58-1.43)$ & $1.34(0.76-2.36)$ & 0.493 \\
\hline \multicolumn{6}{|l|}{ Postmenopausal women } \\
\hline Person-years & 55,340 & 62,053 & 83,802 & 34,097 & \\
\hline No. of breast cancers & 12 & 14 & 37 & 14 & \\
\hline Age-adjusted HR (95\% CI) & 1.00 & $1.04(0.48-2.25)$ & $2.04(1.06-3.91)$ & $1.92(0.88-4.16)$ & 0.015 \\
\hline Multivariable HR $(95 \% \mathrm{CI})^{\mathrm{a})}$ & 1.00 & $1.09(0.45-2.63)$ & $2.49(1.94-5.20)$ & $2.38(1.01-5.64)$ & 0.005 \\
\hline Multivariable HR $(95 \% \mathrm{CI})^{\mathrm{b})}$ & 1.00 & $1.10(0.42-2.88)$ & $2.54(1.11-5.80)$ & $2.37(0.92-6.10)$ & 0.009 \\
\hline$p_{\text {interaction }}$ & & & & & 0.287 \\
\hline \multicolumn{6}{|l|}{ Body mass index $<23.0 \mathrm{~kg} / \mathrm{m}^{2}$} \\
\hline Person-years & 91,438 & 96,675 & 118,411 & 40,682 & \\
\hline No. of breast cancers & 23 & 30 & 50 & 15 & \\
\hline Age-adjusted HR (95\% CI) & 1.00 & $1.26(0.73-2.17)$ & $1.86(1.13-3.06)$ & $1.85(1.13-3.06)$ & 0.009 \\
\hline Multivariable HR $(95 \% \mathrm{CI})^{\mathrm{a})}$ & 1.00 & $1.05(0.59-1.87)$ & $1.68(1.00-2.83)$ & $1.25(0.58-2.70)$ & 0.099 \\
\hline Multivariable HR $(95 \% \mathrm{CI})^{\mathrm{b})}$ & 1.00 & $1.06(0.59-1.90)$ & $1.68(0.98-2.87)$ & $1.24(0.57-2.72)$ & 0.105 \\
\hline \multicolumn{6}{|l|}{ Body mass index $\geq 23.0 \mathrm{~kg} / \mathrm{m}^{2}$} \\
\hline Person-years & 55,580 & 69,838 & 98,307 & 36,363 & \\
\hline No. of breast cancers & 23 & 28 & 50 & 28 & \\
\hline Age-adjusted HR (95\% CI) & 1.00 & $0.99(0.57-1.72)$ & $1.26(0.77-2.07)$ & $1.92(1.10-3.36)$ & 0.018 \\
\hline Multivariable HR $(95 \% \text { CI })^{\mathrm{a})}$ & 1.00 & $0.47(0.12-1.86)$ & $1.92(0.75-4.89)$ & $1.98(0.67-5.83)$ & 0.048 \\
\hline Multivariable HR $(95 \% \mathrm{CI})^{\mathrm{b})}$ & 1.00 & $0.80(0.44-1.47)$ & $0.97(0.56-1.70)$ & $1.26(0.65-2.44)$ & 0.076 \\
\hline$p_{\text {interaction }}$ & & & & & 0.348 \\
\hline
\end{tabular}

$\mathrm{HR}$, hazard ratio; CI, confidence interval. a)Adjusted for age, age of menarche, body mass index, parity, family history of breast cancer, education level, married status, daytime napping, sleep duration, mental stress, alcohol intake, hormone use, smoking status and history of diabetes (for postmenopausal women adjusted further for age of menopause, type of menopause), b) Adjusted further for sport time (never, $1-2,3-4$, and $\geq 5 \mathrm{hr} / \mathrm{wk}$ ) and walking time (never, $<30,30-60$, and $\geq 60$ $\min /$ day). 
as total women, postmenopausal women who watch TV for longer duration were more likely to have earlier menarche.

With reference to women whose TV viewing time was $<1.5 \mathrm{hr} /$ day, those with longer TV viewing time had a higher risk of breast cancer. The associations were slightly attenuated after controlling for indices of physical activity; sport time per week and walking time per day (Table 2). In total women, the multivariable HRs (95\% CIs) of breast cancer in reference to TV viewing time $<1.5 \mathrm{hr}$ / day were 0.89 (0.59-1.34) for 1.5 to $<3.0 \mathrm{hr} /$ day, $1.19(0.82-1.74)$ for 3.0 to $<4.5 \mathrm{hr} /$ day, and 1.45 (0.91-2.32) for $\geq 4.5 \mathrm{hr} /$ day, but the trend was of a borderline statistical significance ( $\mathrm{p}$ for trend $=0.053$ ).

Table 3 shows the stratification analyses by menopausal status and BMI. The positive associations between TV viewing time and risk of breast cancer were found only among postmenopausal women: the multivariable HRs ( $95 \%$ CIs) of breast cancer were $1.10(0.42-2.88)$ for 1.5 to $<3.0 \mathrm{hr} /$ day, 2.54 (1.11-5.80) for 3.0 to $<4.5 \mathrm{hr} /$ day, and 2.37 (0.92-6.10) for $\geq 4.5 \mathrm{hr} /$ day TV viewing time ( $\mathrm{p}$ for trend $=0.009$ ). We found no significant trend for TV viewing time and breast cancer incidence among premenopausal women ( $\mathrm{p}$ for trend $=0.493$ ); however, the interaction by menopausal status was also not statistically significant ( $p_{\text {interaction }}=0.287$ ). On the other hand, baseline BMI levels did not significantly modify the association between TV viewing time and breast cancer incidence ( $\mathrm{p}$ for trend $=0.105 \mathrm{in}$ women with $\mathrm{BMI}<23 \mathrm{~kg} / \mathrm{m}^{2}$, and $\mathrm{p}$ for trend $=0.076$ in women with $\left.\mathrm{BMI} \geq 23 \mathrm{~kg} / \mathrm{m}^{2}\right)$ ( p interaction $=$ $0.348)$.

\section{Discussion}

In the current study, we observed a positive trend for higher risk of breast cancer incidence across increasing TV viewing time categories with a borderline significance among total women and reached a level of significance among postmenopausal women after adjusting for physical activity and other potential confounders.

In the past few decades, a large number of epidemiological studies have been conducted to elaborate the impact of physical activity [7-10], sedentary time [11-13], and specifically TV viewing time [11] on women's risk of breast cancer. The findings have suggested a protective effect of physical activity against risk of breast cancer [7-10], but non-conclusive findings were reported regarding the impact of sedentary time including TV viewing hours [2,14]. A meta-analysis of 21 studies with 34 reports showed that the odds ratio (ORs) for breast cancer were 1.08 (95\% CI, 0.98 to 1.19) for the longest ( $\geq 9 \mathrm{hr} /$ day) vs. shortest $(\leq 1 \mathrm{hr} /$ day) categories of leisure sedentary behavior including TV viewing time, and 1.10 (95\% CI, 1.02 to 1.18) for the longest ( $\geq 5 \mathrm{hr} /$ day) vs. shortest ( $\leq 1 \mathrm{hr} /$ day) categories of occupational sedentary behaviour [14]. Schmid and Leitzmann [2] reported in a meta-analysis of 43 observational studies that the relative risks of breast cancer were 1.07 (95\% CI, 0.92 to 1.23 ) for the longest ( $\geq 9 \mathrm{hr} /$ day $)$ vs. shortest $(0 \mathrm{hr} /$ day $)$ TV viewing time categories, and 1.20 (95\% CI, 0.98 to 1.48) for the highest $(\geq 12 \mathrm{hr} /$ day) vs. lowest $(0 \mathrm{hr} /$ day) sitting time categories. The report from the Southern Community Cohort Study showed the OR for risk of breast cancer was 0.97 (95\% CI, 0.70 to 1.35 ; $\mathrm{p}$ for trend $=0.31$ ) for $\geq 5 \mathrm{hr} /$ day TV viewing time compared with $\leq 2 \mathrm{hr} /$ day [7]. In that report, white women in the longest $(\geq 12 \mathrm{hr} /$ day $)$ vs. shortest $(<5.5 \mathrm{hr} /$ day $)$ quartiles of sedentary behaviour had higher risk of breast cancer (OR, 2.04; 95\% CI, 1.07 to 3.86); however, this association was attenuated slightly after adjusting for physical activity (OR, 1.94; $95 \%$ CI, 1.01 to 3.70) [7]. The adjustment for physical activity attenuated the association between longer TV viewing time and risk of breast cancer in total women of our study to a borderline significant trend but the association remained significant in postmenopausal women. Our findings were consistent with the results from a cohort study of African American women which indicated positive trends for breast cancer risk across TV viewing time among total and postmenopausal women, but not among premenopausal women. In reference to watching TV for $<1 \mathrm{hr} /$ day, the multivariable HRs (95\% CIs) were 0.89 (0.73-1.09) for 1-2 hr / day, 0.96 (0.791.17) for $3-4 \mathrm{hr} /$ day and 1.11 (0.89-1.38) for $\geq 5 \mathrm{hr} /$ day in total women ( $\mathrm{p}$ for trend=0.04); the respective HRs were 0.83 (0.60-1.14), 0.95 (0.69-1.30), and 1.10 (0.79-1.53) in postmenopausal women ( $\mathrm{p}$ for trend $=0.05)$; and $0.80(0.61-1.05), 0.84$ (0.65-1.12), and $1.03(0.76-1.41)$ ( $\mathrm{p}$ for trend=0.42) in premenopausal women [11].

Several studies have suggested biological pathways (obesity and metabolic dysfunction) by which less active behaviors at occupational and leisure times can associate with augmented risk of breast cancer [16,17]. For example, each hourly increment in TV viewing time was associated with a $0.5 \mathrm{~kg} / \mathrm{m}^{2}$ higher BMI and $1.18 \mathrm{~cm}$ greater waist circumference from the Australian Diabetes, Obesity and Lifestyle (AusDiab) study [17]. Higher levels of adiposity, particularly central adiposity which is common in postmenopausal women due to lack of estrogen $[18,19]$ have been associated with estrogen receptor-positive carcinogenic tumors [19]. In JACC study, weight gain since age 20 was associated with increased risk of breast cancer for postmenopausal women, the multivariable HRs (95\% CIs) of breast cancer in reference to weight gain since age $20 \mathrm{for}<3.3 \mathrm{~kg}$ were $1.45(0.78-2.70)$ for 3.3-6.6 kg, 2.48 (1.40-4.41) for 6.7-9.9 kg, and 2.94 (1.844.70 ) for $\geq 10.0 \mathrm{~kg}$ ( $\mathrm{p}$ for trend $<0.001$ ) [20]. Women in the longest TV viewing time category had higher BMI levels, and 
in an additional analysis of our data, we found each 1-SD increment of BMI $\left(3.11 \mathrm{~kg} / \mathrm{m}^{2}\right)$ was associated with $43 \%$ increased risk of breast cancer; yet, interactions with BMI or weight gain since age 20 in the association between TV viewing time and risk of breast cancer were not statistically significant.

The metabolic dysfunctions (higher levels of fasting glucose, C-reactive protein, insulin, and HOMA-IR), that have been evident with longer duration in front of TV $[16,17]$, serve as another biological pathway between TV viewing time and risk of breast cancer. Phosphorylation of both insulin receptor-B and insulin growth factor 1 receptor by insulin binding leads to cellular and tumor growth via the activation of the mitogen-activated protein kinase (MAPKERK) pathway [21]. Also, insulin can interact with estrogen to stimulate tumor growth via the estrogen receptor pathway [22]. HOMA-IR, the biomarker of insulin resistance, has been implicated in the development and progression of breast cancer [23]. A study from the Australian Diabetes, Obesity and Lifestyle Study suggested that long TV viewing time can be associated with breast cancer risk by greater HOMA-IR [17]. In our study, since a history of diabetes was more prevalent among women in the longer TV viewing time categories, women viewing TV for longer time may be more likely to have pre-clinical metabolic dysfunctions that enhance the development of breast cancer.

TV viewing has been also associated with higher consumption of unhealthy foods such as fast foods, sugar-sweetened beverages and sweets [24]. Consumption of energy-dense foods and sugary drinks could enhance carcinogenesis not only via promoting weight gain and adiposity [25], but also via increasing circulating levels of insulin-like growth factor 1 , sex hormone-binding globulin and estrogen [26]. A casecontrol study of 1456 postmenopausal European Americans showed that breast cancer risk was higher with frequent consumptions of energy-dense foods (OR, 2.95; 95\% CI, 1.66 to 5.22 , for the highest [ $>11$ times/wk] vs. lowest [ $\leq 3$ times/ wk] quartiles of intake), fast foods (OR, 2.35; 95\% CI, 1.38 to 4.00 , for the highest [ $>5$ times / wk] vs. lowest $[\leq 1$ time/ wk] quartiles of intake), and sugary drinks (OR, 2.05; 95\% CI, 1.13 to 3.70, for $>3$ times / wk vs. none) [25]. On the other hand, postmenopausal Japanese women in the highest quartile of vegetable fat intake demonstrated two-fold increase in breast cancer risk (95\% CI, 1.05 to 4.13) compared with those in the lowest quartile of intake [27]. Postmenopausal Japanese women in the highest vs. lowest quintiles of westernised dietary pattern had a $29 \%$ increased risk of breast cancer (95\% CI, 0.99 to 1.76; $\mathrm{p}$ for trend=0.04) [28]. Last, TV viewing time is related to likelihood of smoking initiation [29] that can increase the risk of breast cancer [30]. The proportion of current smokers was higher with longer TV viewing time in the current study.
The strengths of our study were recruiting women from the general population, the large sample size to satisfy the statistical power and the availability of the control for information on other risk factors for breast cancer and potential confounding factors. Moreover, this study was derived from prospective cohort design, which is less subjective to recall and selection bias compared to case-control studies.

There are several limitations in this study: First, because we collected information about menopausal status at the baseline survey, the possibility of misclassification of menopausal status at the onset of breast cancer should be considered. Second, the self-reported nature of both TV viewing time measure and important covariates such as reproductive factors and physical activity, collected only at baseline and not updated during the follow-up is susceptible to reporting error and biases [24]. This may have reduced the true magnitude of the association between the exposure and outcome variables due to regression dilution bias. However, the misclassification would be non-differential regarding the exposure and confounding variables because participants could not foresee subsequent events at baseline. Third, TV viewing time is not always a good indicator of total sedentary time, using a questionnaire covering broad domains of sedentary behaviors such as the IPAQ (the International Physical Activity Questionnaire), which is used widely in international studies is suggested for future studies. Last, in our stratified analysis by BMI, we used $23 \mathrm{~kg} / \mathrm{m}^{2}$ (the World Health Organization Western Pacific Regional Office criteria for overweight) [31] as a cut-off point instead of the cut off point for obesity in Asians, $25 \mathrm{~kg} / \mathrm{m}^{2}$ because the median BMI of our sample was $22.98 \mathrm{~kg} / \mathrm{m}^{2}$ and to assure reasonable number of cases in each category of TV viewing time. However, stratified analysis by $25 \mathrm{~kg} / \mathrm{m}^{2}$ BMI showed the same results.

In summary, prolonged TV viewing time was associated with increased risk of breast cancer incidence among Japanese women, especially postmenopausal women. Health education to women about the need for shorter TV viewing time is suggested, and further research is needed to confirm the observed associations.

\section{Conflicts of Interest}

Conflict of interest relevant to this article was not reported.

\section{Acknowledgments}

The authors thank all staff members involved in this study for their valuable help in conducting the baseline survey and followup.

This work was supported by Grants-in-Aid for Scientific Research from the Ministry of Education, Culture, Sports, Science and Tech- 
nology of Japan (MEXT) (Monbusho); Grants-in-Aid for Scientific Research on Priority Areas of Cancer; and Grants-in-Aid for Scientific Research on Priority Areas of Cancer Epidemiology from MEXT (MonbuKagaku-sho) (Nos. 61010076, 62010074, 63010074, 1010068, 2151065, 3151064, 4151063, 5151069, 6279102, 11181101, 17015022, 18014011, 20014026, 20390156, and 26293138), Comprehensive Research on Cardiovascular and Life-Style Related Diseases (H26Junkankitou [Seisaku]-Ippan-001and H29-Junkankitou [Seishuu]Ippan-003), JSPS KAKENHI Grant Number JP 16H06277, and Grants-in-Aid for China Scholarship Council (CSC file No. 201608050113).

\section{The members of the JACC study group}

Dr. Akiko Tamakoshi (present chairperson of the study group), Hokkaido University Graduate School of Medicine, Dr. Mitsuru Mori, Sapporo Medical University School of Medicine, Dr. Yoshihiro Kaneko, Akita University Graduate School of Medicine, Dr. Ichiro Tsuji, Tohoku University Graduate School of Medicine, Dr. Yosikazu Nakamura, Jichi Medical School, Dr. Hiroyasu Iso, Osaka University School of Medicine, Dr. Kazumasa Yamagishi, Faculty of Medicine, University of Tsukuba, Dr. Haruo Mikami, Chiba Cancer Center, Dr. Michiko Kurosawa, Juntendo University School of Med- icine Dr. Yoshiharu Hoshiyama, Yokohama Soei University, Dr. Naohito Tanabe, University of Niigata Prefecture, Dr. Koji Tamakoshi, Nagoya University Graduate School of Health Science, Dr. Kenji Wakai, Nagoya University Graduate School of Medicine, Dr. Shinkan Tokudome, National Institute of Health and Nutrition, Dr. Koji Suzuki, Fujita Health University School of Health Sciences, Drs. Shuji Hashimoto and Hiroshi Yatsuya, Fujita Health University School of Medicine, Dr. Shogo Kikuchi, Aichi Medical University School of Medicine, Dr. Yasuhiko Wada, Faculty of Nutrition, University of Kochi, Dr. Takashi Kawamura, Kyoto University Health Service, Dr. Yoshiyuki Watanabe, Kyoto Prefectural University of Medicine Graduate School of Medical Science, Dr. Kotaro Ozasa, Radiation Effects Research Foundation, Dr. Kazuya Mikami, Kyoto Prefectural University of Medicine Graduate School of Medical Science, Dr. Chigusa Date, School of Human Science and Environment, University of Hyogo, Dr. Kiyomi Sakata, Iwate Medical University, Dr. Yoichi Kurozawa, Tottori University Faculty of Medicine, Drs. Takesumi Yoshimura and Yoshihisa Fujino, University of Occupational and Environmental Health, Dr. Akira Shibata, Kurume University, Dr. Naoyuki Okamoto, Kanagawa Cancer Center, and Dr. Hideo Shio, Long-Term Care Health Facility Caretown Minamikusatsu, Shiga, Japan

\section{References}

1. Clark BK, Healy GN, Winkler EA, Gardiner PA, Sugiyama T, Dunstan DW, et al. Relationship of television time with accelerometer-derived sedentary time: NHANES. Med Sci Sports Exerc. 2011;43:822-8.

2. Schmid D, Leitzmann MF. Television viewing and time spent sedentary in relation to cancer risk: a meta-analysis. J Natl Cancer Inst. 2014;106:dju098.

3. American time use survey: 2007 results [Internet]. Washington, DC: U.S. Department of Labor; 2008 [cited 2017 Mar 20]. Available from: https://www.bls.gov/news.release/archives / atus_06252008.pdf.

4. Japan Broadcasting Culture Research Institute. National Lifetime Study [Internet]. Tokyo: Japan Broadcasting Corporation; 2010 [cited 2017 Mar 20]. Available from: http://www.nhk. or.jp/bunken/summary/yoron/lifetime/pdf/110223.pdf.

5. Matsuda A, Matsuda T, Shibata A, Katanoda K, Sobue T, Nishimoto $\mathrm{H}$, et al. Cancer incidence and incidence rates in Japan in 2008: a study of 25 population-based cancer registries for the Monitoring of Cancer Incidence in Japan (MCIJ) project. Jpn J Clin Oncol. 2014;44:388-96.

6. Minami Y, Tsubono Y, Nishino Y, Ohuchi N, Shibuya D, Hisamichi $S$. The increase of female breast cancer incidence in Japan: emergence of birth cohort effect. Int J Cancer. 2004;108: 901-6.

7. Cohen SS, Matthews CE, Bradshaw PT, Lipworth L, Bucho- wski MS, Signorello LB, et al. Sedentary behavior, physical activity, and likelihood of breast cancer among Black and White women: a report from the Southern Community Cohort Study. Cancer Prev Res (Phila). 2013;6:566-76.

8. Marcus PM, Newman B, Moorman PG, Millikan RC, Baird DD, Qaqish B, et al. Physical activity at age 12 and adult breast cancer risk (United States). Cancer Causes Control. 1999;10: 293-302.

9. Mathew A, Gajalakshmi V, Rajan B, Kanimozhi VC, Brennan $\mathrm{P}$, Binukumar BP, et al. Physical activity levels among urban and rural women in south India and the risk of breast cancer: a case-control study. Eur J Cancer Prev. 2009;18:368-76.

10. Dirx MJ, Voorrips LE, Goldbohm RA, van den Brandt PA. Baseline recreational physical activity, history of sports participation, and postmenopausal breast carcinoma risk in the Netherlands Cohort Study. Cancer. 2001;92:1638-49.

11. Nomura SJ, Dash C, Rosenberg L, Palmer J, Adams-Campbell LL. Sedentary time and breast cancer incidence in African American women. Cancer Causes Control. 2016;27:1239-52.

12. Pronk A, Ji BT, Shu XO, Chow WH, Xue S, Yang G, et al. Physical activity and breast cancer risk in Chinese women. Br J Cancer. 2011;105:1443-50.

13. Kruk J. Lifetime occupational physical activity and the risk of breast cancer: a case-control study. Asian Pac J Cancer Prev. 2009;10:443-8 
14. Zhou Y, Zhao H, Peng C. Association of sedentary behavior with the risk of breast cancer in women: update meta-analysis of observational studies. Ann Epidemiol. 2015;25:687-97.

15. Tamakoshi A, Ozasa K, Fujino Y, Suzuki K, Sakata K, Mori M, et al. Cohort profile of the Japan Collaborative Cohort Study at final follow-up. J Epidemiol. 2013;23:227-32.

16. Lynch BM, Friedenreich CM, Winkler EA, Healy GN, Vallance JK, Eakin EG, et al. Associations of objectively assessed physical activity and sedentary time with biomarkers of breast cancer risk in postmenopausal women: findings from NHANES (2003-2006). Breast Cancer Res Treat. 2011;130:183-94.

17. Wiseman AJ, Lynch BM, Cameron AJ, Dunstan DW. Associations of change in television viewing time with biomarkers of postmenopausal breast cancer risk: the Australian Diabetes, Obesity and Lifestyle Study. Cancer Causes Control. 2014; 25:1309-19.

18. Lovejoy JC, Champagne CM, de Jonge L, Xie H, Smith SR. Increased visceral fat and decreased energy expenditure during the menopausal transition. Int J Obes (Lond). 2008;32:94958.

19. Cleary MP, Grossmann ME. Minireview: obesity and breast cancer: the estrogen connection. Endocrinology. 2009;150:253742.

20. Nitta J, Nojima M, Ohnishi H, Mori M, Wakai K, Suzuki S, et al. Weight gain and alcohol drinking associations with breast cancer risk in Japanese postmenopausal women: results from the Japan Collaborative Cohort (JACC) study. Asian Pac J Cancer Prev. 2016;17:1437-43.

21. Tao Y, Pinzi V, Bourhis J, Deutsch E. Mechanisms of disease: signaling of the insulin-like growth factor 1 receptor pathway: therapeutic perspectives in cancer. Nat Clin Pract Oncol. 2007;4:591-602.

22. Rose DP, Vona-Davis L. The cellular and molecular mecha- nisms by which insulin influences breast cancer risk and progression. Endocr Relat Cancer. 2012;19:R225-41.

23. Renehan AG, Roberts DL, Dive C. Obesity and cancer: pathophysiological and biological mechanisms. Arch Physiol Biochem. 2008;114:71-83.

24. Lipsky LM, Iannotti RJ. Associations of television viewing with eating behaviors in the 2009 Health Behaviour in Schoolaged Children Study. Arch Pediatr Adolesc Med. 2012;166: 465-72.

25. Chandran U, McCann SE, Zirpoli G, Gong Z, Lin Y, Hong CC, et al. Intake of energy-dense foods, fast foods, sugary drinks, and breast cancer risk in African American and European American women. Nutr Cancer. 2014;66:1187-99.

26. Harvie M, Howell A. Energy balance adiposity and breast cancer: energy restriction strategies for breast cancer prevention. Obes Rev. 2006;7:33-47.

27. Wakai K, Tamakoshi K, Date C, Fukui M, Suzuki S, Lin Y, et al. Dietary intakes of fat and fatty acids and risk of breast cancer: a prospective study in Japan. Cancer Sci. 2005;96:590-9.

28. Shin S, Saito E, Inoue M, Sawada N, Ishihara J, Takachi R, et al. Dietary pattern and breast cancer risk in Japanese women: the Japan Public Health Center-based Prospective Study (JPHC Study). Br J Nutr. 2016;115:1769-79.

29. Gidwani PP, Sobol A, DeJong W, Perrin JM, Gortmaker SL. Television viewing and initiation of smoking among youth. Pediatrics. 2002;110:505-8.

30. Goldvaser H, Gal O, Rizel S, Hendler D, Neiman V, Shochat $\mathrm{T}$, et al. The association between smoking and breast cancer characteristics and outcome. BMC Cancer. 2017;17:624.

31. WHO Expert Consultation. Appropriate body-mass index for Asian populations and its implications for policy and intervention strategies. Lancet. 2004;363:157-63. 